\title{
Correlation between lymphatic endothelial markers and lymph node status or N-staging of colorectal cancer
}

\author{
Xing-mao Zhang ${ }^{1}$, Wen-xiao Han², Hong-ying Wang ${ }^{2}$ and Qiang He ${ }^{1 *}$
}

\begin{abstract}
Background: The purpose of this study is to examine the expression levels of lymphatic endothelial markers in colorectal cancer and to explore the correlation between the expression levels of markers and lymph node status.

Methods: Forty-seven paired fresh tumor tissues and para-cancerous tissues were collected from colorectal cancer patients who received surgical treatment between August 2015 and March 2016 in Cancer Hospital, Chinese Academy of Medical Sciences. Real-time quantitative PCR (RTQ-PCR) was used to check the expression levels of LYVE-1, VEGFR-3, Podoplanin, and Prox-1 in tumor and para-cancerous tissues.

Results: The positive expression rates of LYVE-1, VEGFR-3, Podoplanin, and Prox-1 in tumor tissues were 100, 93.6, 100, and $91.4 \%$, but 100, 100, 100, and $87.2 \%$ in para-cancerous tissues. Comparing with para-cancerous tissues, tumor tissues had significantly lower expression levels of LYVE-1 $(P<0.001)$ and VEGFR-3 $(P=0.013)$ and higher levels of Podoplanin $(P=0.016)$ and Prox-1 $(P=0.078)$. There was no correlation between lymph node status and the expression level of LYVE-1 in tumor tissues $(P=0.354)$ or par-cancerous tissues $(P=0.617)$; similar results were found for VEGFR-3 $(P=0.631,0.738)$, Podoplanin $(P=0.490,0.625)$, and Prox $-1(P=0.503,0.174)$. Meanwhile, there was no correlation between $\mathrm{N}$-staging and the expression level of LYVE-1 in tumor tissues $(P=0.914)$ or paracancerous tissues $(P=0.784)$; similar results were found for VEGFR-3 $(P=0.493,0.955)$, Podoplanin $(P=0.199,0.370)$, and Prox-1 $(P=0.780,0.234)$.

Conclusions: There was no correlation between expression levels of lymphatic endothelial markers and lymph node status; LYVE-1, VEGFR-3, Podoplanin, and Prox-1 could not be used for predicting the lymph node status or $\mathrm{N}$-staging of colorectal cancer.
\end{abstract}

Keywords: LYVE-1, VEGFR-3, Podoplanin, Prox-1, Colorectal cancer, RTQ-PCR

\section{Background}

Lymphatic system markers which have been used for studying the mechanism of lymphatic metastasis for several kinds of malignant tumors recently include lymphatic endothelial markers and lymphatic endothelial growth factors, and the lymphatic endothelial markers mainly include lymphatic vessel endothelial hyaluronic acid receptor-1 (LYVE-1), vascular endothelial growth factor receptor 3 (VEGFR-3), Podoplanin, and Prox-1 $[1,2]$. The correlation between the lymphatic endothelial

\footnotetext{
* Correspondence: heqiang_cy@163.com

${ }^{1}$ Department of Hepatobiliary Surgery, Beijing Chaoyang Hospital, Capital Medical University, Beijing, China

Full list of author information is available at the end of the article
}

markers and lymphatic metastasis in some malignant tumors such as gastric cancer, breast cancer, ovarian cancer, and so on have been studied by some centers, and there is no consensus yet whether lymphatic endothelial markers can be used for predicting the $\mathrm{N}$-staging of carcinoma [3-7]. In this study, we used real-time quantitative PCR (RTQ-PCR) to examine the expression of the four kinds of lymphatic endothelial markers in colorectal cancer; meanwhile, we analyzed the difference of expression levels in tumor tissue and para-cancerous tissue and we also analyzed the correlation between the expression levels of LYVE-1, VEGFR-3, Podoplanin, or Prox-1 and lymph node status. 


\section{Methods}

\section{Tissue collection}

Forty-seven paired fresh tumor tissues and paracancerous tissues (2-cm tissue adjacent to cancer) were collected from colorectal cancer patients who received surgical treatment between August 2015 and March 2016 in Cancer Hospital, Chinese Academy of Medical Sciences. All tissues were collected within half an hour after the removal of specimens. RNA was extracted using the standard RNAzol procedure. cDNA was subsequently synthesized using a reverse transcription kit according to the manufacturer's instructions.

\section{Primers}

Primers of four markers were synthesized by Sangon Biotech (Shanghai) Co., Ltd: LYVE-1 forward primer: $5^{\prime}-$ AAGAATGAAGCTGCTGGGTTT-3', LYVE-1 reverse primer: 5'-GACATAGCAAAATCCAAGACCA-3'; VEG FR-3 forward primer: 5'-AGGGAGACGCCCTTTCA TG-3', VEGFR-3 reverse primer: 5'-GAGGGCTCTT TGGTCAAGCA-3'; Podoplanin forward primer: 5'CACGGAGAAAGTGGATGGAGA-3', Podoplanin reverse primer: 5'-GCCGATGGCTAGTAAGACCC-3'; Prox-1 forward primer: 5'-AAAGCAAAGCTCATGT TTTTTTATA-3', Prox-1 reverse primer: 5'-GTAAAA CTCACGGAAATTGCTAAA-3'.

\section{RTQ-PCR}

Bio-Rad CFX96 real-time PCR system was used for RTQ-PCR; relative quantitative analysis was proceeded according to the SYBR Green I method. Reaction system was as follows: SsoFastTM EvaGreen supermix $10 \mu \mathrm{l}$, forward primer of target gene $2 \mu \mathrm{l}(2 \mu \mathrm{M})$, reverse primer $2 \mu \mathrm{l}(2 \mu \mathrm{M})$, deionized water $4 \mu \mathrm{l}$, and cDNA $2 \mu \mathrm{l}$. RTQ-PCR conditions were as follows: 40 cycles, predegeneration $95{ }^{\circ} \mathrm{C}$ for $30^{\prime}$, degeneration $95^{\circ} \mathrm{C}$ for $10^{\prime}$, and annealing extension $60^{\circ} \mathrm{C}$ for $10^{\prime}$.

\section{Statistical analysis}

Statistical analyses were performed using statistical software package SPSS version 16.0. A $P$ value less than 0.05 was considered to be statistically significant. Student's $t$ test was used for the analysis of continuous variables, and one-way ANOVA was used for the analysis between groups.

\section{Results}

Twenty-eight of the 47 patients were males and 19 were females in this study. Their ages ranged from 34 to 84 with the median age of 56.3. The number of patients with ascending colon cancer, transverse colon cancer, descending colon cancer, sigmoid colon cancer, and rectal cancer were $7,2,1,8$, and 29 , respectively. Lymph node involvement was detected in 27 patients. The general parameters of patients were shown in Table 1 .

\section{Different expressions of the four markers between tumor tissues and para-cancerous tissues \\ Expression rates in tumor tissues and para-cancerous tissues}

Both of the positive expression rates of LYVE-1 in tumor tissues and para-cancerous tissues were 100\%, and the same results could be found for Podoplanin. A

Table 1 The general parameters of patients in this study

\begin{tabular}{|c|c|}
\hline Parameters & \\
\hline \multicolumn{2}{|l|}{ Gender, case } \\
\hline Male & 29 \\
\hline Female & 18 \\
\hline Age, year, mean (range) & $56.3(34-84)$ \\
\hline \multicolumn{2}{|l|}{ Location of tumors, case } \\
\hline Cecum & 0 \\
\hline Ascending colon & 7 \\
\hline Transverse colon & 2 \\
\hline Descending colon & 1 \\
\hline Sigmoid colon & 8 \\
\hline Rectum & 29 \\
\hline Tumor size, cm, mean (range) & $4.8(2.2-14.0)$ \\
\hline \multicolumn{2}{|l|}{ Type of pathology, case } \\
\hline Adenocarcinoma & 44 \\
\hline Mucinous adenocarcinoma & 1 \\
\hline Signet ring cell carcinoma & 2 \\
\hline \multicolumn{2}{|l|}{ Degree of differentiation, case } \\
\hline Well & 3 \\
\hline Moderate & 34 \\
\hline Poor & 10 \\
\hline \multicolumn{2}{|l|}{ Depth of invasion, case } \\
\hline $\mathrm{T} 2$ & 2 \\
\hline T3 & 38 \\
\hline T4a & 7 \\
\hline \multicolumn{2}{|l|}{$\mathrm{N}$-staging, case } \\
\hline No & 20 \\
\hline N1a & 7 \\
\hline $\mathrm{N} 1 \mathrm{~b}$ & 5 \\
\hline $\mathrm{N} 2 \mathrm{a}$ & 8 \\
\hline $\mathrm{N} 2 \mathrm{~b}$ & 7 \\
\hline \multicolumn{2}{|l|}{ TNM staging, case } \\
\hline Ila & 18 \\
\hline$\| \mathrm{b}$ & 2 \\
\hline$\| l \mid b$ & 18 \\
\hline IIIc & 9 \\
\hline
\end{tabular}


93.6\% positive expression rate of VEGFR-3 was found in tumor tissue, but $100 \%$ in para-cancerous tissue. Prox -1 had a positive expression rate of $91.4 \%$ in tumor tissue and $87.2 \%$ in para-cancerous tissue.

\section{Expression levels in tumor tissues and para-cancerous tissues}

Expression level of LYVE-1 in para-cancerous tissues was significantly higher than that in tumor tissues $(P<$ 0.001 ), and a higher expression level VEGFR-3 was also found in para-cancerous tissues compared with that in tumor tissues $(P=0.013)$, whereas a different result was found for Podoplanin, the higher expression level was checked in tumor tissues $(P=0.016)$. For Prox -1 , there were no significantly different expression levels in between tumor tissues and para-cancerous tissues (Fig. 1).

\section{The correlation between lymph node status and} expression levels of markers

The expression level of LYVE-1 in tumor tissues of patients with lymph node involvement was similar with that in patients without lymph node involvement $(P=0.354)$, and the similar results were found for VEGFR-3 $(P=0.631)$, Podoplanin $(P=0.490)$, and Prox $-1(P=0.503)$. Similarly, the expression level of LYVE-1 in para-cancerous tissues of $\mathrm{N}(+)$ staging patients was similar with that in $\mathrm{N}(-)$ staging patients $(P=0.617)$; the similar results were found for VEGFR-3 $(P=0.738)$, Podoplanin $(P=0.625)$, and Prox $-1(P=0.174)$ (Fig. 2).

\section{The correlation between $\mathrm{N}$-staging and expression level of markers}

The difference of expression level of LYVE-1 in tumor tissues of patients with N1a, N1b, N2a, and N2b staging was not found $(P=0.914)$; same results were found for VEGFR-3 $(P=0.493)$, Podoplanin $(P=0.199)$, and Prox$1(P=0.780)$. No difference was found for LYVE-1 in para-cancerous tissues $(P=0.784)$; similarly, no differences for VEGFR-3 $(P=0.955)$, Podoplanin $(P=0.370)$, and Prox $-1(P=0.234)$ (Fig. 3$)$.

\section{Discussion}

The discovery of lymphatic system markers is promoting the research progress of metastatic mechanism. The correlation between lymphatic endothelial markers and lymphatic metastasis had been reported by several centers during the last decade. However, there is no consensus yet whether lymphatic endothelial markers can be used for predicting lymphatic status.

LYVE-1, as a new hyaluronic acid receptor, was found in 1999 [8]. It mainly expressed in lymphatic endothelial

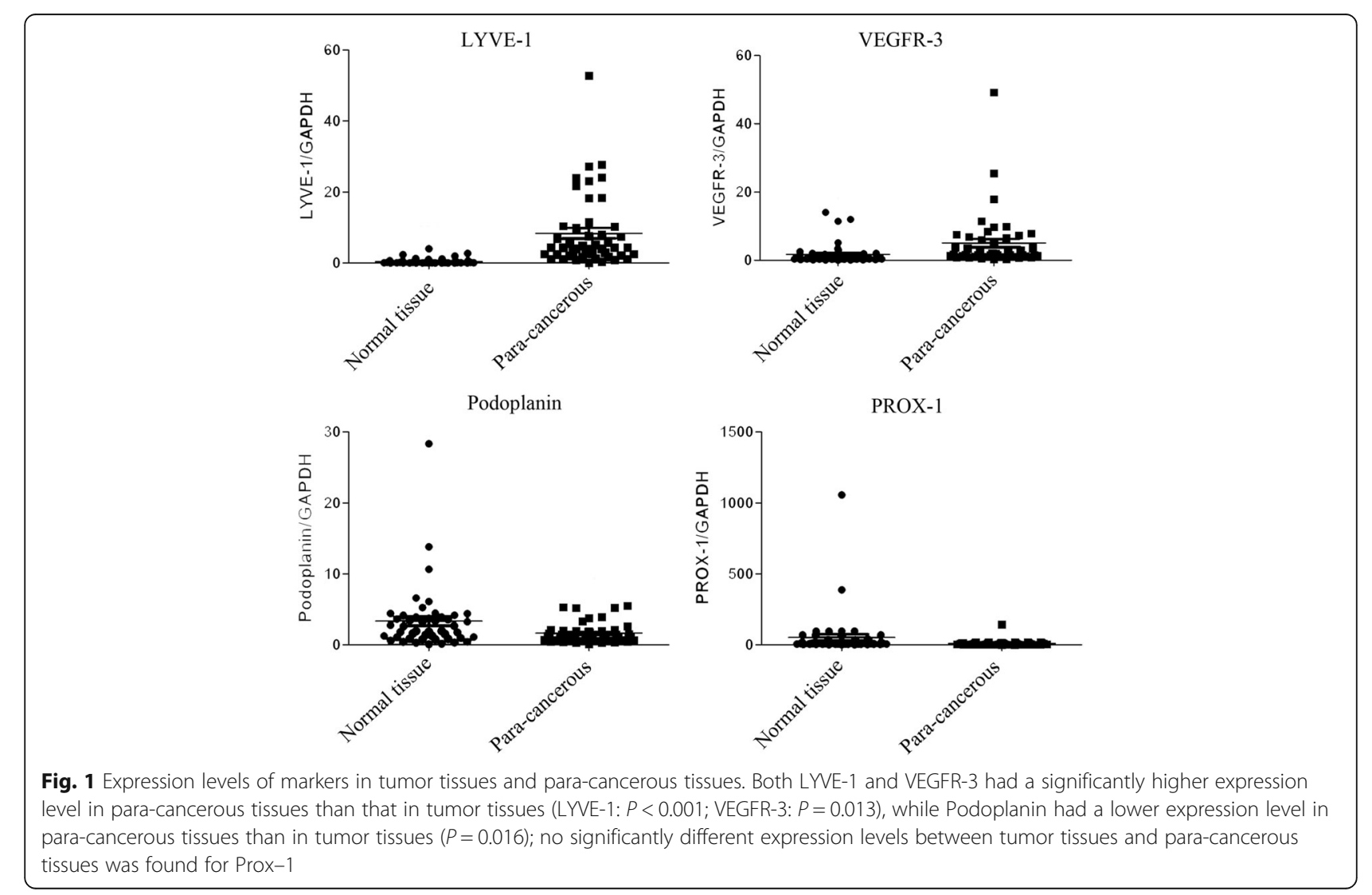



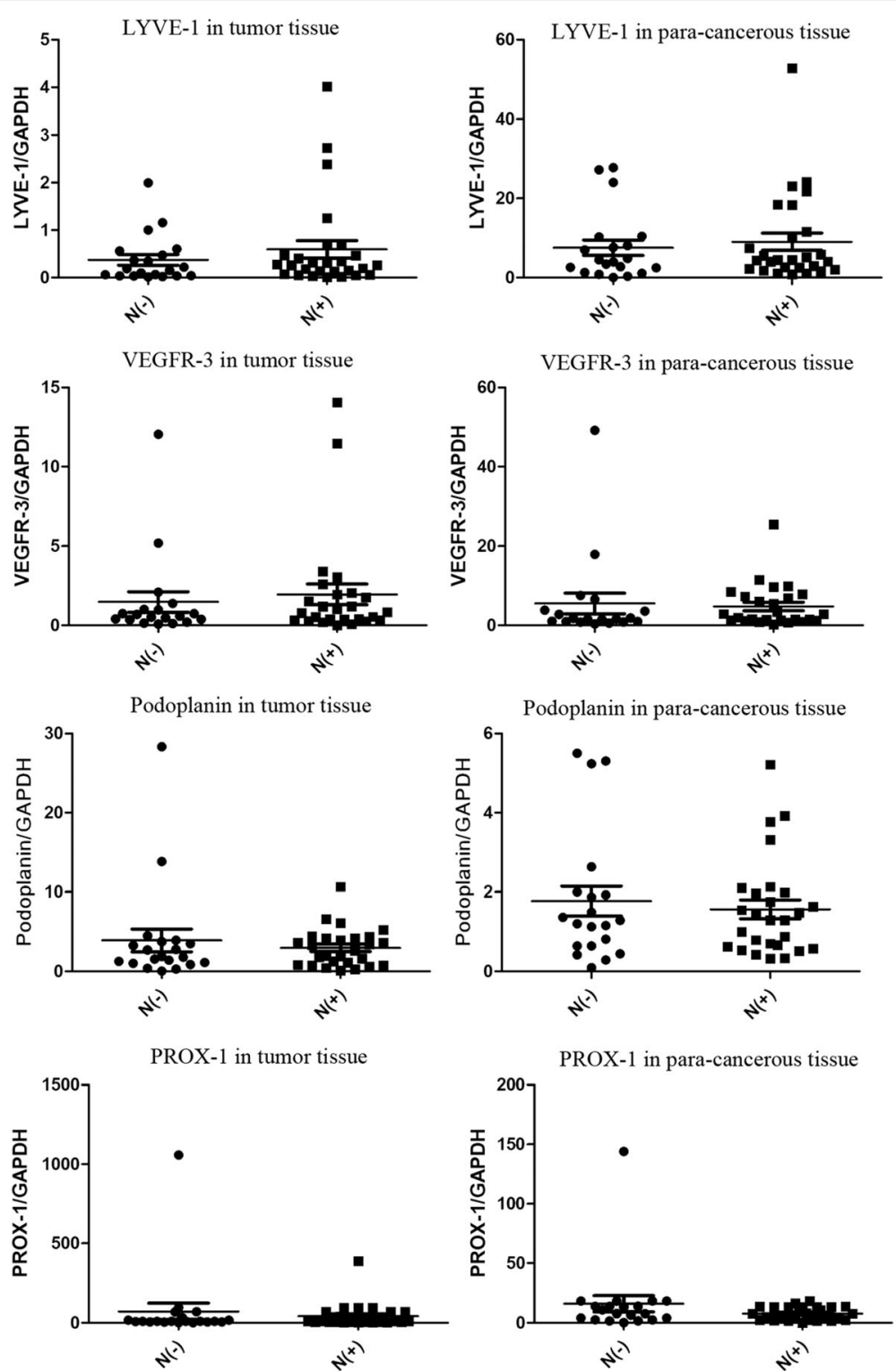

Fig. 2 Correlation between lymph node status and expression levels of markers in tumor tissues or para-cancerous tissues. Status of lymph node did not influence the expression level of the four makers; no significantly different expression levels were found in tumor tissues and no obvious differences in para-cancerous tissues. (In tumor tissues: LYVE-1, $P=0.354$; VEGFR-3, $P=0.631$; Podoplanin, $P=0.490$; Prox-1, $P=0.503$; in paracancerous: LYVE-1, $P=0.617$; VEGFR-3, $P=0.738$; Podoplanin, $P=0.625$; Prox $-1, P=0.174$ )

cells $[9,10]$. Some studies showed that lymphatic endothelial cells of malignant tumors had specific expression of LYVE-1 [11]. Expression of LYVE-1 in gastric cancer was studied by Ozmen et al. [12]; his results showed that the expression level of LYVE-1 in cancer tissues was obviously higher than that in para-cancerous tissues, and an increased expression level was related with the increased proportion of lymph node involvement. In 2006, Gao et al. [13] designed a study to examine the expression of LYVE-1 in colorectal cancer tissues and normal tissues; his results showed that the expression level of
LYVE-1 in cancer tissues was higher than that in normal tissues although no significant difference was found. A PCR study designed by Lu et al. [14] confirmed that LYVE-1 mainly existed in margins of tumor.

Among all lymphatic endothelial markers, VEGFR-3 was discovered earliest. VEGFR-3 has vital function during the process of generation and development of vascular system $[15,16]$. A study designed by Kawakami et al. [5] found that the positive rate of VEGFR-3 in colorectal cancer tissues was 79.2\%; meanwhile, his study confirmed that there was no correlation between 

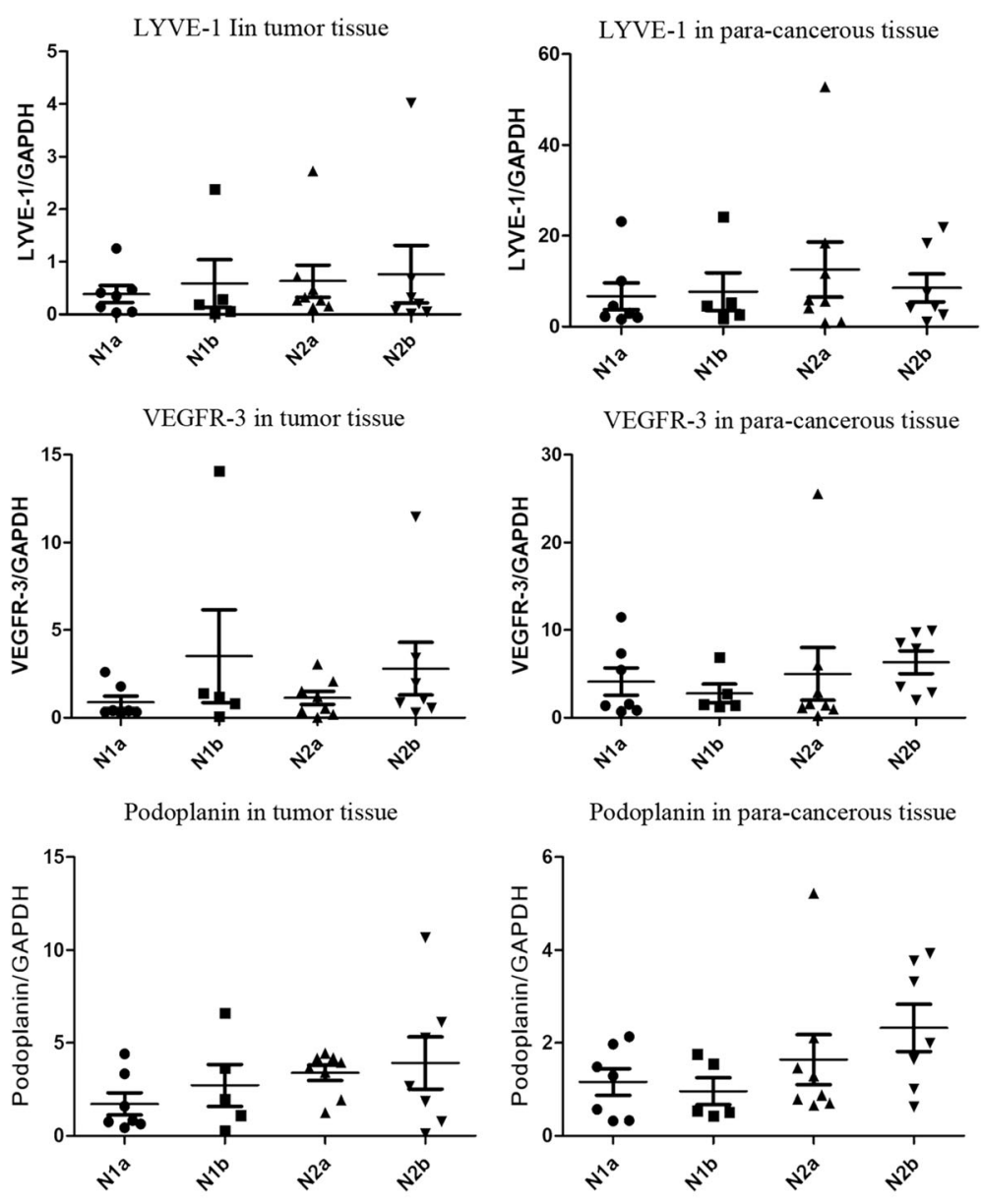

Podoplanin in para-cancerous tissue
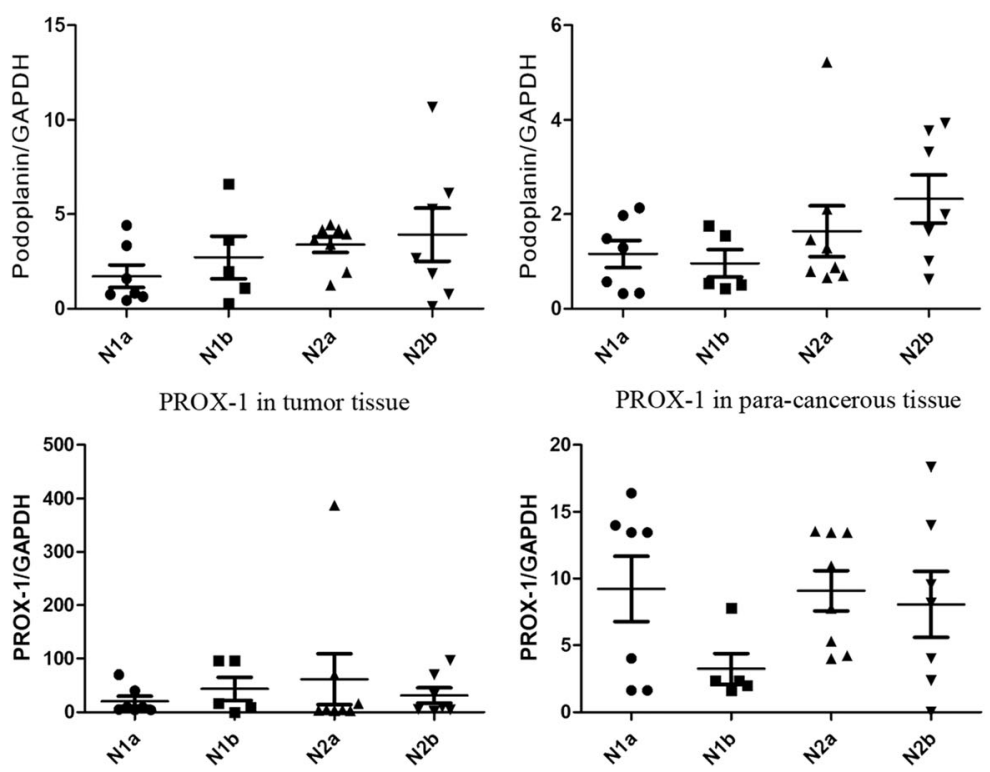

Fig. 3 Correlation between $\mathrm{N}$-staging and expression levels of markers in tumor tissues or para-cancerous tissues. The expression levels of these four makers in tumor tissues or para-cancerous tissues were not impacted by N-staging of tumor. (In tumors tissues: LYVE-1, $P=0.914 ;$ VEGFR-3, $P$ $=0.493$; Podoplanin, $P=0.199 ;$ Prox-1, $P=0.780$; in para-cancerous: LYVE-1, $P=0.784$; VEGFR-3, $P=0.955$; Podoplanin, $P=0.370 ;$ Prox-1, $P=0.234$ )

the expression level of VEGFR-3 in cancer tissues and lymph node involvement; however, different conclusion was made by some other professors: some studies showed that an increased rate of lymph nodes involvement was related to the higher expression level of VEGFR-3 in colorectal cancer tissues [17, 18].

Initially, the Podoplanin was found on the surface of glomerular podocytes, and its expression in lymphatic endothelial cells was firstly reported in 1999 [19]. Podoplanin mainly exists in small lymphatic vessels, but it does not express in big lymphatic vessels with smooth muscle. Braun et al. [20] found that Podoplanin was a sensitive factor for predicting the involvement of lymph nodes in invasive breast cancer; the study of Wada et al. [21] demonstrated that the expression level of Podoplanin was related to the involvement rate of lymph nodes and lymphovascular invasion in $\mathrm{T} 1$ stage colorectal cancer.

Prox -1 , as one kind of nuclear transcription factors, is the homologous gene of prospero got from Drosophila 
melanogaster; it has the functions of regulating cell mitosis and inducing the differentiation of lymphatic endothelial cells [22]. Parr et al. [23] found that colorectal cancer tissues had a higher expression level of Prox-1; the study results of Agarwal et al. [7] showed that breast cancer with lymph node involvement had a higher expression level of Prox-1 in cancer tissues.

Some similar or different results were found based on our study; all of the four markers had the high positive expression rates not only in tumor tissues but also in para-cancerous cancer tissues, and the expression levels of LYVE-1 and VEGFR-3 was higher in para-cancerous tissues than that in tumor tissues, whereas the higher expression levels of Podoplanin and Prox-1 was found in tumor tissues. There was no correlation between lymph node status and the expression level of LYVE-1 in tumor tissues or para-cancerous tissues; similar results were found for VEGFR-3, Podoplanin, and Prox-1. Meanwhile, no correlation between $\mathrm{N}$-staging and the expression level of LYVE-1 in tumor tissues or paracancerous tissues; similar results were found for VEGFR-3, Podoplanin, and Prox-1.

\section{Conclusions}

There was no correlation between lymph node status and expression of LYVE-1, VEGFR-3, Podoplanin, or Prox-1; these four lymphatic endothelial markers could not be used for predicting the lymph node status or $\mathrm{N}$ staging of colorectal cancer.

\section{Abbreviations}

LYVE-1: Lymphatic vessel endothelial hyaluronic acid receptor-1; VEGFR3: Vascular endothelial growth factor receptor 3

\section{Acknowledgements}

The authors thank Hu Jun-jie, Zeng Wei-gen, and Shi Lei for collecting the data; their supports are the key factor for the completion of the manuscript.

\section{Funding}

None

\section{Availability of data and materials}

Not applicable

\begin{abstract}
Authors' contributions
HQ and ZXM provided the concept; ZXM and WHY were the major contributors in writing the manuscript; $\mathrm{HQ}$ and $\mathrm{HWX}$ analyzed and interpreted the patient data; all authors read and approved the final manuscript.
\end{abstract}

\section{Ethics approval and consent to participate}

Not applicable

\section{Consent for publication}

Not applicable

\section{Competing interests}

The authors declare that they have no competing interests.

\section{Publisher's Note}

Springer Nature remains neutral with regard to jurisdictional claims in published maps and institutional affiliations.

\section{Author details}

'Department of Hepatobiliary Surgery, Beijing Chaoyang Hospital, Capital Medical University, Beijing, China. ${ }^{2}$ State Key Laboratory of Molecular Oncology, Cancer Institute and Cancer Hospital, Chinese Academy of Medical Sciences, Peking Union Medical College, Beijing, China.

Received: 2 July 2017 Accepted: 15 November 2017

Published online: 21 November 2017

\section{References}

1. Sundar SS, Zhang H, Brown P, Manek S, Han C, Kaur K, et al. Role of lymphangiogenesis in epithelial ovarian cancer. Br J Cancer. 2006;94:1650-7.

2. Sundar SS, Ganesan TS. Role of lymphangiogenesis in cancer. J Clin Oncol. 2007;25:4298-307.

3. Hall FT, Freeman JL, Asa SL, Jackson DG, Beasley NJ. Intratumoral lymphatics and lymph node metastases in papillary thyroid carcinoma. Arch Otolaryngol Head Neck Surg. 2003;129:716-9.

4. Beasley NJ, Prevo R, Banerji S, Leek RD, Moore J, van Trappen P, et al. Intratumoral lymphangiogenesis and lymph node metastasis in head and neck cancer. Cancer Res. 2002;62:1315-20.

5. Kawakami M, Furuhata T, Kimura Y, Yamaguchi K, Hata F, Sasaki K, et al. Quantification of vascular endothelial growth factor- $C$ and its receptor-3 messenger RNA with real-time quantitative polymerase chain reaction as a predictor of lymph node metastasis in human colorectal cancer. Surgery. 2003;133:300-8

6. Yamanashi T, Nakanishi Y, Fujii G, Akishima-Fukasawa Y, Moriya Y, Kanai Y, et al. Podoplanin expression identified in stromal fibroblasts as a favorable prognostic marker in patients with colorectal carcinoma. Oncology. 2009;77: 53-62.

7. Agarwal B, Saxena R, Morimiya A, Mehrotra S, Badve S. Lymphangiogenesis does not occur in breast cancer. Am J Surg Pathol. 2005;29:1449-55.

8. Banerji S, Ni J, Wang SX, Clasper S, Su J, Tammi R, et al. LYVE-1, a new homologue of the CD44 glycoprotein, is a lymph-specific receptor for hyaluronan. J Cell Biol. 1999;144:789-801.

9. Schledzewski K, Falkowski M, Moldenhauer G, Metharom P, Kzhyshkowska J, Ganss R, et al. Lymphatic endothelium-specific hyaluronan receptor LYVE-1 is expressed by stabilin-1+, F4/80+, CD11b+ macrophages in malignant tumours and wound healing tissue in vivo and in bone marrow cultures in vitro: implications for the assessment of lymphangiogenesis. J Pathol. 2006; 209:67-77.

10. Wu M, Du Y, Liu Y, He Y, Yang C, Wang W, et al. Low molecular weight hyaluronan induces lymphangiogenesis through LYV-1-mediated signaling pathways. PLoS One. 2014;9:e92857.

11. Cunnick GH, Jiang WG, Gomez KF, Mansel RE. Lymphangiogenesis quantification using quantitative PCR and breast cancer as a model. Biochem Biophys Res Commun. 2001;288:1043-6.

12. Ozmen F, Ozmen MM, Ozdemir E, Moran M, Seckin S, Guc D, et al. Relationship between LWE-1, VEGFR-3 and CD44 gene expressions and lymphatic metastasis in gastric cancer. World J Gastroenterol. 2011;17:3220-8.

13. Gao F, Lu YM, Cao ML, Liu YW, He YQ, Wang Y. Expression and quantification of LYVE-1 in human colorectal cancer. Clin Exp Med. 2006;6:65-71.

14. Lu Y, Yang Q, Du Y, Feng G, Yang C. Expression analysis of lymphangiogenic factors in human colorectal cancer with quantitative RT-PCR. Cancer Investig. 2007;25:393-6.

15. Pajusola K, Aprelikova O, Korhonen J, Kaipainen A, Pertovaara L, Alitalo R, et al. FLT4 receptor tyrosine kinase contains seven immunoglobulin-like loops and is expressed in multiple human tissues and cell lines. Cancer Res. 1992;52:5738-43.

16. Galland F, Karamysheva A, Pebusque MJ, Borg JP, Rottapel R, Dubreuil P, et al. The FLT4 gene encodes a transmembrane tyrosine kinase related to the vascular endothelial growth factor receptor. Oncogene. 1993:8:1233-40.

17. Okita NT, Yamada Y, Takahari D, Hirashima Y, Matsubara J, Kato K, et al. Vascular endothelial growth factor receptor expression as a prognostic marker for survival in colorectal cancer. Jpn J Clin Oncol. 2009;39:595-600.

18. Smith NR, Baker D, James NH, Ratcliffe K, Jenkins M, Ashton SE, et al. Vascular endothelial growth factor receptors VEGFR-2 and VEGFR-3 are 
localized primarily to the vasculature in human primary solid cancers. Clin Cancer Res. 2010;16:3548-61.

19. Roy S, Chu A, Trojanowski JQ, Zhang PJ. D2-40, a novel monoclonal antibody against the M2A antigen as a marker to distinguish hemangioblastomas from renal cell carcinomas. Acta Neuropathol. 2005;109:497-502.

20. Braun M, Flucke U, Debald M, Walgenbach-Bruenagel G, Walgenbach KJ, Holler T, et al. Detection of lymphovascular invasion in early breast cancer by D2-40 (podoplanin): a clinically useful predictor for axillary lymph node metastases. Breast Cancer Res Treat. 2008;112:503-11.

21. Wada H, Shiozawa M, Katayama K, Okamoto N, Miyagi Y, Rino Y, et al. Systematic review and meta-analysis of histopathological predictive factors for lymph node metastasis in T1 colorectal cancer. J Gastroenterol. 2015;50: 727-34

22. Wigle JT, Harvey N, Detmar M, Lagutina I, Grosveld G, Gunn MD, et al. An essential role for Prox1 in the induction of the lymphatic endothelial cell phenotype. EMBO J. 2002;21:1505-13.

23. Parr C, Jiang WG. Quantitative analysis of lymphangiogenic markers in human colorectal cancer. Int J Oncol. 2003;23:533-9.

Submit your next manuscript to BioMed Central and we will help you at every step:

- We accept pre-submission inquiries

- Our selector tool helps you to find the most relevant journal

- We provide round the clock customer support

- Convenient online submission

- Thorough peer review

- Inclusion in PubMed and all major indexing services

- Maximum visibility for your research

Submit your manuscript at www.biomedcentral.com/submit
Biomed Central 